\title{
Decomposição e liberação de nutrientes da palhada de braquiária, sorgo e soja em áreas de plantio direto no cerrado goiano
}

\author{
Litter decomposition and nutrient release from Brachiaria, \\ Sorghum and soybean in no-tillage areas in the Cerrado region, \\ Goiás
}

\author{
Celeste Queiroz Rossi ${ }^{1}$; Marcos Gervasio Pereira ${ }^{2 *}$; Simone Guimarães Giácomo ${ }^{3}$; \\ Marconi Betta ${ }^{4}$; José Carlos Polidoro 5
}

\section{Resumo}

\begin{abstract}
A avaliação da decomposição dos resíduos vegetais adicionados ao solo pelas plantas de cobertura permite uma melhor compreensão do fornecimento de nutrientes para as culturas de interesse comercial. O objetivo do trabalho foi avaliar as taxas de decomposição e a dinâmica da liberação de N, P e K de resíduos culturais na entressafra da soja cultivada em Latossolo Vermelho, sob plantio direto. Os resíduos utilizados foram braquiária (Brachiaria ruziziensis R. Germ. \& Evrard) e o sorgo (Sorghum bicolor L. Moench). A produção média de biomassa seca de braquiária + soja foi de $6,1 \mathrm{Mg} \mathrm{ha}^{-1}$ e do sorgo + soja foi de $3,8 \mathrm{Mg} \mathrm{ha}^{-1}$. A decomposição da matéria seca e a liberação de nutrientes foram monitoradas aos 15 , 30, 60, 90, 120 dias por meio de sacolas contendo resíduos culturais depositados na superfície do solo. Utilizou-se um modelo matemático exponencial negativo simples para descrever a decomposição dos resíduos e a liberação de N, P, K, sendo calculados a constante de decomposição (k) e o tempo de meiavida $\left(\mathrm{T}^{1 / 2}\right)$. Os valores de $\mathrm{T}^{1 / 2}$ da matéria seca foram de $154 \mathrm{e} 258$ dias para braquiária + soja e sorgo + soja, respectivamente, no período seco e de 99 e 119 dias no período chuvoso. O nutriente que apresentou o menor $\mathrm{T}^{1 / 2}$ foi o $\mathrm{P}$, seguido por $\mathrm{K}$ e $\mathrm{N}$ nos dois resíduos avaliados e nas diferentes épocas.
\end{abstract}

Palavras-chave: Resíduos culturais, cerrado, tempo de meia vida

\begin{abstract}
The evaluation of plant litter decomposition added to the soil by cover crops provides a better understanding of nutrient supply to crops of commercial interest. The objective of this study was to evaluate the decomposition rate and dynamics of release of $\mathrm{N}, \mathrm{P}$ and $\mathrm{K}$ in crop residues from crop of soybeans grown in Oxisol under no tillage. The residues used were Congo grass (Brachiaria ruziziensis) and sorghum (Sorghum bicolor L. Moench). The average production of Congo grass biomass + soybean was $6.1 \mathrm{Mg} \mathrm{ha}^{-1}$ and soybean + sorghum was $3.8 \mathrm{Mg} \mathrm{ha}^{-1}$. The dry matter decomposition and nutrient release were monitored at 15,30,60,90,120 days using bags containing residues deposited on the soil surface. A mathematical model was used to describe the litter decomposition and N, P, K release and the decomposition constant $(\mathrm{k})$ and half-life $\left(\mathrm{T}^{1 / 2}\right)$ were calculated. The values of $\mathrm{T}^{1 / 2}$ for dry matter were 154 and 258 days for Brachiaria + soybean and soybean + sorghum, respectively, in the dry season and 99 and 119 days in the rainy season. The nutrient with the lowest $\mathrm{T}^{1 / 2}$ was $\mathrm{P}$, followed by $\mathrm{K}$ and $\mathrm{N}$ in both litters and evaluated at different times.
\end{abstract}

Key words: Crop residues, Brazilian savana, half-life

\footnotetext{
${ }^{1}$ Eng $^{\mathrm{a}}$ Agr ${ }^{\mathrm{a}}$, Discente de Doutorado no Curso de Pós Graduação em Agronomia, Ciência do Solo, CPGA-CS, Universidade Federal Rural do Rio de Janeiro, UFRRJ, Seropédica, RJ. E-mail: celestqrossi@yahoo.com.br

2 Prof. Dr. do Dept $^{\circ}$ de Solos da UFRRJ, Seropédica, RJ. E-mail: mgervasiopereira@gmail.com

${ }^{3}$ Eng $^{\text {a Agra }}$, UFRRJ, Seropédica, RJ. E-mail: sigiacomo@yahoo.com.br

${ }^{4}$ Eng $^{\mathrm{o}} \mathrm{Agr}^{\mathrm{o}}$, Universidade de Rio Verde, FESURV, Fazenda Fontes do Saber, Rio Verde, GO. E-mail: marconibetta@yahoo.com.br

${ }^{5}$ Eng $^{\circ}$ Agr $^{\circ}$, Dr. Pesquisador da Embrapa Solos, Rio de Janeiro, RJ. E-mail: polidoro@embrapa.cnps.br

* Autor para correspondência
} 


\section{Introdução}

O Cerrado é o segundo maior bioma brasileiro, ocupando uma área de aproximadamente $21 \%$ do território nacional (BORLAUG, 2002). O clima dessa região é sazonal, com duas estações bem definidas: a primeira caracterizada por um período chuvoso, que dura de outubro a março, e a segunda, por um período seco, de abril a setembro.

Os solos do Cerrado, predominantemente LATOSSOLOS VERMELHO e LATOSSOLO VERMELHO-AMARELO, são intemperizados, ácidos, de baixa fertilidade natural e com concentrações elevadas de alumínio (CORREIA; REATTO; SPERA, 2004).

Diversos estudos têm sido realizados nesse bioma com o objetivo de desenvolver estratégias para uma utilização sustentável desses solos, no sentido de reduzir o impacto das atividades agrícolas sobre o ambiente, onde as características de clima e solo (plantio convencional associado com a monocultura) podem levar ao declínio acelerado dos estoques de carbono (C) e nitrogênio (N) de origem orgânica (FREIXO; CANELLAS; MACHADO, 2002; TORRES et. al., 2005).

$\mathrm{O}$ sistema plantio direto (PD) constitui uma importante técnica de manutenção e recuperação da capacidade produtiva de solos degradados, por evitar o revolvimento do solo e manter o resíduos das culturas sobre o solo, protegendo-o de variações de temperatura e ainda reduzindo a oxidação da matéria orgânica no período da entressafra (outono/ inverno) (TORRES et al., 2005). As plantas de cobertura, além de protegerem o solo dos agentes climáticos, seqüestram $\mathrm{C}$ atmosférico $\mathrm{e}$, desta forma, apresentam potencial para manter ou elevar o teor de matéria orgânica, mobilizar e reciclar nutrientes (SILVA et al., 2011).

A região do Cerrado está inserida em ambiente de clima tropical, propiciando que a decomposição da palhada ocorra de maneira acelerada, com valores até 10 vezes superiores comparativamente às regiões temperadas (LAL; LOGAN, 1995). A utilização de plantas de cobertura com elevada produção de resíduos e maiores tempos de meiavida, constitui uma alternativa para proteção do solo, mantendo os resíduos vegetais sobre o mesmo por maior tempo (CERETTA et. al., 2002).

A rotação e o consórcio de culturas podem ser adotadas juntamente com o PD, estabelecendo-se, previamente, uma sequência de plantas de famílias diferentes. Como resultado, tem-se aumento nos quantitativos de resíduos deixados em superfície, o que contribui para melhor eficiência do modelo. De maneira geral, o PD promove aumento do C total do solo nas camadas superficiais, mesmo por um pequeno período de condução (BAYER et. al., 2004). Materiais com alta relação $\mathrm{C} / \mathrm{N}$ são decompostos mais lentamente, podendo produzir coberturas mais permanentes no solo. $\mathrm{O}$ uso de plantas leguminosas destaca-se pela capacidade de assimilação do $\mathrm{N}$ atmosférico, por meio de associações com bactérias diazotróficas do grupo rizóbio, e as gramíneas, por sua vez, pelo acúmulo de fitomassa decorrente da maior relação $\mathrm{C} / \mathrm{N}$.

As características qualitativas dos resíduos vegetais, associadas às condições edafoclimáticas, alteram a velocidade de decomposição dos resíduos orgânicos, refletindo sobre a disponibilidade de nutrientes ao solo (AITA; GIACOMINI, 2003). Neste cenário, a braquiária tem se mostrado eficiente no acúmulo de $\mathrm{C}$ em relação ao cerrado nativo, devido ao seu abundante sistema radicular que apresenta contínua renovação e elevado efeito rizosférico (REID; GOSS, 1980; MOREIRA; SIQUEIRA, 2002).

Neste sentido, o objetivo foi avaliar às taxas de decomposição e a dinâmica da liberação de N, P e $\mathrm{K}$ dos resíduos culturais de braquiária + soja e de braquiária + sorgo em LATOSSOLO VERMELHO no Cerrado Goiano. 


\section{Material e Métodos}

O município de Montividiu (GO) está inserido dentro do bioma do Cerrado e situa-se entre a latitude $17^{\circ} 27^{\prime} \mathrm{S}$ e longitude $51^{\circ} 04^{\prime} \mathrm{W}$. A altitude média verificada na área é de $930 \mathrm{~m}$. O clima da região é do tipo Aw (Köppen) - Tropical, com chuvas concentradas no verão e um período seco bem definido durante o inverno (Figura 1). O estudo foi realizado em duas áreas experimentais da Fazenda Querência das Antas para avaliação de dois sistemas de manejo do plantio direto da cultura da soja: SB - cultivo de soja (Glycine max L.) no período chuvoso e braquiária (Uroclroa ruziziensis) no período seco; SS - cultivo de soja (Glycine $\max$ L.) no período chuvoso e sorgo (Sorghum bicolor L. Moench) variedade DKB 599 no período seco. O solo foi classificado como LATOSSOLO VERMELHO (EMPRESA BRASILEIRA DE PESQUISA AGROPECUÁRIA, 2006).

Figura 1. Dados climáticos mensais de temperatura e precipitação pluviométrica (janeiro de 2007 a dezembro de 2008), extraídos da Estação Meteorológica da Universidade de Rio Verde, localizada próxima ao município de Montividiu - GO.

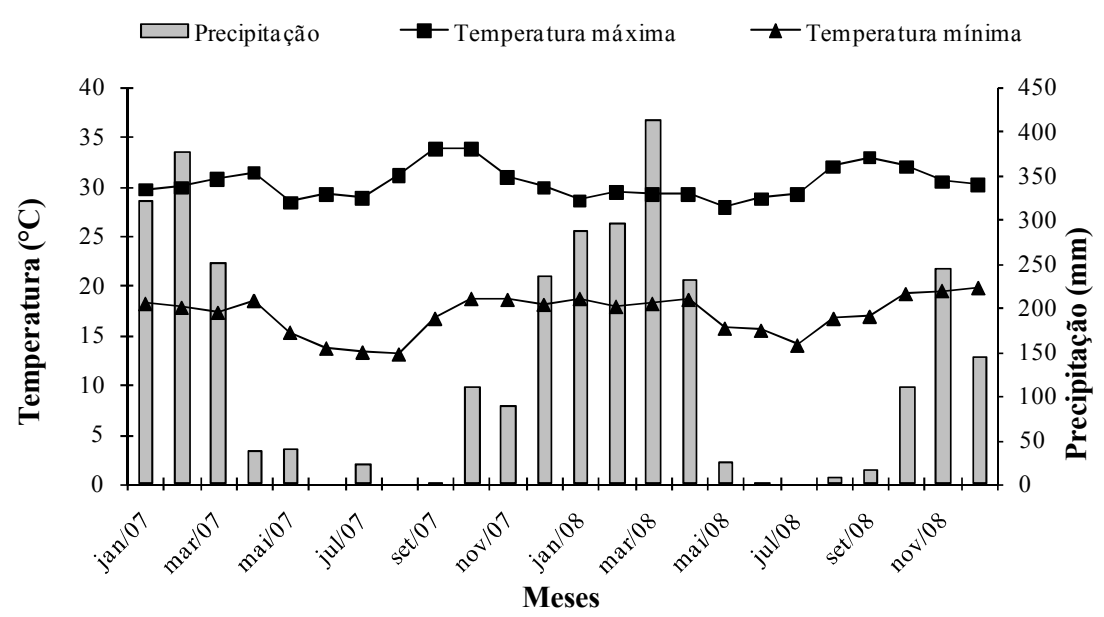

Fonte: Elaboração dos autores.

A soja foi cultivada comercialmente nas áreas de estudo; em uma das áreas no período da entressafra, nenhuma planta de interesse comercial foi cultivada, deixando-se que a braquiária se estabeler durante todo o período de seca na região. Na outra área foi realizado o cultivo de sorgo para produção de grãos em sucessão à soja.

A primeira amostragem dos resíduos vegetais foi realizada no início de março de 2007, após a colheita da soja, da safra 2006/2007; a segunda coleta foi realizada ao final de outubro de 2007 , coincidindo com o final do período seco da região, quando a braquiária foi manejada com herbicidas dissecantes (Glyphosate e 2,4-D), para a implantação da lavoura de soja da safra 2007/2008. As áreas de estudo foram adubadas com $82 \mathrm{~kg} \mathrm{ha}^{-1}$ de $\mathrm{KCl}$ e $332 \mathrm{~kg} \mathrm{ha}^{-1}$ do formulado 02-23-08 (N-P $\left.\mathrm{O}_{5}-\mathrm{K}_{2} \mathrm{O}\right)$.

A produtividade da soja das áreas na safra 2006/2007 foi de 3,78 e 3,63 $\mathrm{Mg}$ grãos ha $^{-1}$ e na safra 2007/2008 de 3,54 e 3,39 Mg grãos ha-1 para os tratamentos SB e SS respectivamente. 
Cada área de estudo apresentava tamanho de $2500 \mathrm{~m}^{2}$, parcelas de $50 \mathrm{~m} \times 50 \mathrm{~m}$. Após a colheita da soja, foi realizada uma amostragem dos resíduos vegetais em oito pontos na área experimental, com o auxílio de um gabarito (quadrado metálico de 1 $\mathrm{m}^{2}$ ), lançado aleatoriamente, sendo coletado todo o material vegetal contido na área delimitada por este gabarito. Os resíduos foram secos a $65^{\circ} \mathrm{C}$ por $72 \mathrm{~h} \mathrm{em}$ estufa de circulação forçada de ar, e posteriormente pesados para a determinação da produção de massa seca (resíduos culturais).

O delineamento utilizado foi inteiramente casualizado com quatro repetições. Para avaliar a decomposição e liberação de nutrientes, utilizouse o método das bolsas de decomposição ('litter bags') (SILVA et. al., 1997; ESPÍNDOLA et. al., 1998). Estas bolsas foram confeccionadas em nylon ${ }^{\circledR}$ com malha de $2 \mathrm{~mm}$, e área interna de 0,04 $\mathrm{m}^{2}$. Em cada bolsa foram colocadas $20 \mathrm{~g}$ de material fresco composto por soja + braquiária e soja + sorgo. Em seguida, foram distribuídas quatro bolsas aleatoriamente para cada data de coleta, no total de 40 bolsas na primeira amostragem e de 32 bolsas na segunda amostragem na superfície do solo de cada área experimental. Foram realizadas avaliações em duas épocas distintas. A primeira, no período seco (final de março de 2007), com coletas realizadas aos 15, 30, 60, 90 e 120 dias; a segunda, no período chuvoso (novembro de 2007) com coletas aos 15 , 45, 90 e 120 dias após a distribuição das bolsas de decomposição.

O material coletado também foi seco em estufa de circulação forçada ( $65{ }^{\circ} \mathrm{C}$ até peso constante) para a determinação da matéria seca remanescente por diferença de pesagem. Em seguida, o material seco foi triturado em moinho tipo Willey e, posteriormente determinado os teores de N-total, pelo método de Kjeldahl (HILDEBRAND, 1976), e os teores de P e K, segundo Tedesco et al. (1995).

A partir dos resultados obtidos foram determinadas as taxas de decomposição da biomassa e de liberação de nutrientes da massa remanescente, utilizando-se o modelo matemático exponencial negativo simples descrito por Thomas e Asakawa (1993):

$$
\mathrm{C}=\text { Co. } \mathrm{e}^{-\mathrm{kt}}
$$

Onde C é a quantidade de massa seca, ou nutrientes remanescentes, depois de um período de tempo t, em dias; Co refere-se à quantidade de massa seca no início da decomposição; $\mathrm{k}$ é a constante de decomposição.

O tempo de meia vida $\left(\mathrm{T}^{1 / 2}\right)$, tempo necessário para decomposição de $50 \%$ da massa, foi calculado a partir dos valores $\mathrm{k}$ do modelo matemático onde:

$$
\mathrm{T}^{1 / 2}=\ln 0,5 / \mathrm{k}
$$

Na análise de variância das taxas de decomposição e de liberação de nutrientes, aplicou-se o teste F com $5 \%$ de probabilidade com a utilização do Software Sigma Plot 8.

\section{Resultados e Discussão}

A produção de biomassa seca na área onde se utiliza a braquiária como planta de cobertura foi superior à área de sorgo (Figura 2), diferindo, dos resultados obtidos por outros autores. Torres e Pereira (2008), estudando a dinâmica do K de resíduos de cobertura vegetal no Cerrado verificaram tendência contrária, ou seja, valores de biomassa seca de braquiária $\left(6,0 \mathrm{Mg} \mathrm{ha}^{-1}\right)$ inferiores ao do sorgo (7,1 Mg ha-1). Kliemann, Braz e Silveira (2006) avaliando as taxas de decomposição de resíduos de espécies de cobertura em LATOSSOLO VERMELHO em sistema de PD no município de Santo Antônio de Goiás (GO) verificaram a mesma tendência observada no presente trabalho, ou seja, produção de biomassa seca de braquiária superior $\left(12,42 \mathrm{Mg} \mathrm{ha}^{-1}\right)$ a do sorgo $\left(6,75 \mathrm{Mg} \mathrm{ha}^{-1}\right)$, sendo que a magnitude destes valores foi praticamente $o$ dobro da observada nesta pesquisa.

Nunes et. al. (2006) e Crusciol e Soratto (2007) quantificaram valores de biomassa seca de 6,2 $\mathrm{Mg} \mathrm{ha}{ }^{-1}$ semelhantes aos encontrados no presente 
trabalho. No que se refere especificamente ao sorgo, Moraes (2001) observou valores de biomassa seca de $10,7 \mathrm{Mg} \mathrm{ha}^{-1}$ e Oliveira (2001) valores de 15,5
$\mathrm{Mg} \mathrm{ha}^{-1}$. Entretanto, esses elevados valores estavam relacionados a rebrota da cultura.

Figura 2. Valores médios de massa seca $\left(\mathrm{Mg} \mathrm{ha}^{-1}\right)$ nos dois sistemas avaliados. *Média significativa pelo teste $\mathrm{F} 5 \%$ de probabilidade. SB: sistemas soja/braquiária; SS: sistema soja/sorgo.

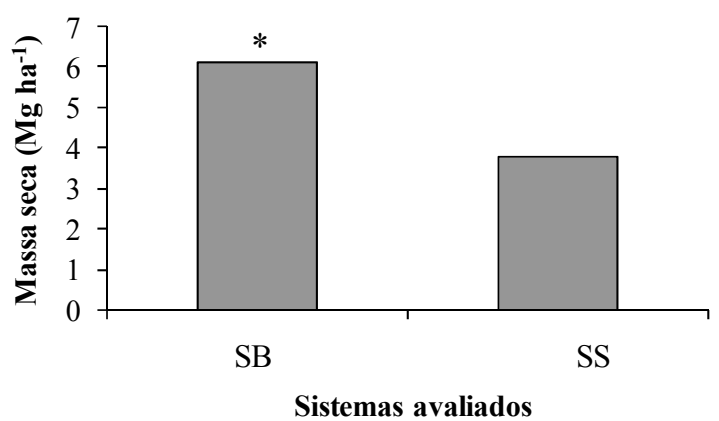

Fonte: Elaboração dos autores.

Nos dois sistemas de manejo, a cinética do processo de decomposição dos resíduos culturais apresentou um padrão semelhante, possivelmente pela predominância de resíduos de soja em ambos os sistemas. Verificou-se uma fase inicial rápida de decomposição seguida de outra mais lenta (Figura $3)$. Resultados semelhantes aos encontrados neste estudo foram relatados por Aita e Giacomini (2003) estudando a dinâmica da decomposição e liberação de nitrogênio de resíduos culturais de plantas de cobertura do solo solteiras e consorciadas na região sul verificaram que a cinética do processo de decomposição apresentou um padrão com uma fase inicial rápida, seguida de uma segunda fase mais lenta. Esses autores observaram que ao final do primeiro mês de avaliação da decomposição no campo, $81 \%$ da matéria seca (MS) inicial da aveia ainda permanecia na superfície do solo contra $57 \%$ da ervilhaca, confirmando resultados de outros estudos em que a taxa de decomposição de leguminosas superou a de gramíneas. Torres et al. (2005) ao avaliarem a decomposição e a liberação de $\mathrm{N}$ de resíduos culturais de plantas de cobertura consorciadas na região do cerrado observaram em todos os tratamentos, que a cinética do processo de decomposição dos diferentes resíduos culturais foi similar, apresentando padrão de decréscimo exponencialmente no decorrer do tempo. Os valores de $\mathrm{T}^{1 / 2}$ da matéria seca foram de 385 e 495 dias para braquiária + soja e sorgo + soja, respectivamente, no período seco e de 99 e 115 dias no período chuvoso (Tabela 1). Observa-se que para o período chuvoso os valores do $\mathrm{T}^{1 / 2}$ foram menores do que aqueles verificados no período seco. As condições de maior precipitação pluviométrica podem favorecer a atividade dos organismos do solo, acelerando o processo de decomposição

A mistura braquiária + soja apresentou menores valores de meia vida quando comparada ao sorgo + soja. Este padrão pode ser atribuído provavelmente à grande quantidade de biomassa acumulada na área de braquiária, que favorece maiores teores de umidade no solo e a atividade microbiana, além da menor relação $\mathrm{C} / \mathrm{N}$ da braquiária quando comparada 
ao sorgo. Esta combinação de fatores acelera o processo de decomposição dos resíduos.

Em estudos de decomposição e liberação de nutrientes de resíduos culturais em áreas de cultivo de soja, Torres et al. (2005) encontraram valores de $\mathrm{T}^{1 / 2}$ para braquiária de 60 dias, e 169 dias para sorgo, inferiores aos verificados neste estudo. Os autores também observaram uma relação $\mathrm{C} / \mathrm{N}$ de 16,1 para a braquiária, e de 24,3 para o sorgo.

Figura 3. Massa seca remanescente dos resíduos de plantas de cobertura nos sistemas soja/braquiária (SB) e soja/ sorgo (SS), avaliados. Avaliações realizadas no campo até 120 dias após a distribuição das bolsas de decomposição na superfície do solo. Acondicionamento das sacolas de decomposição em março de 2007 (a). Acondicionamento das sacolas de decomposição em novembro de 2007 (b).

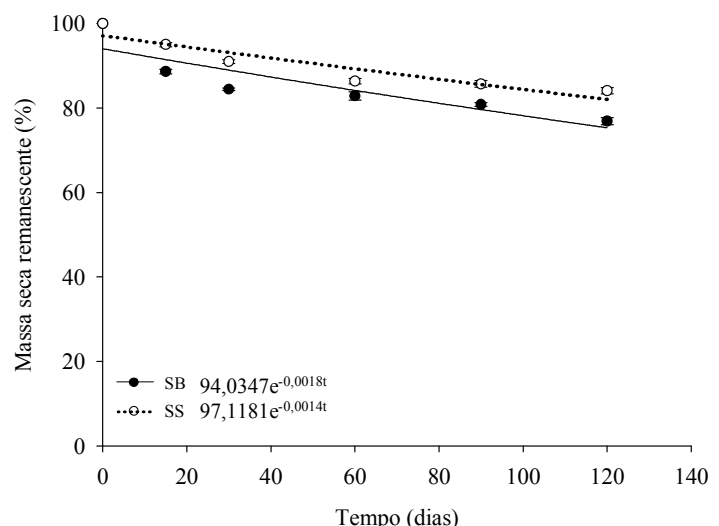

(a)

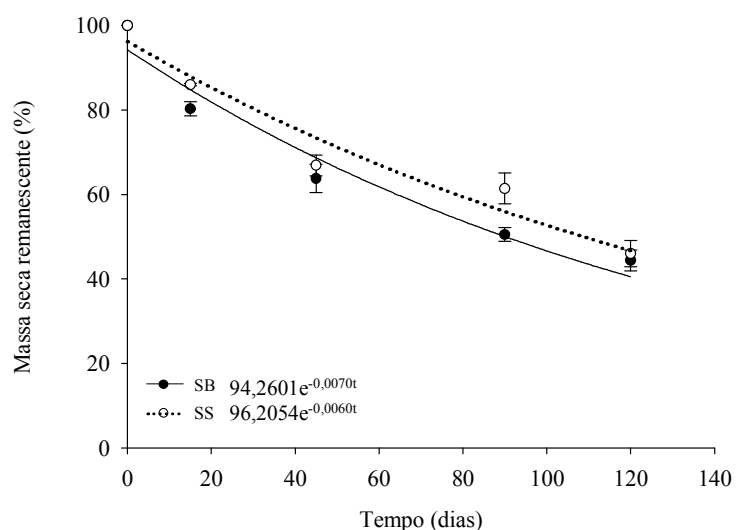

(b)

Fonte: Elaboração dos autores.

Tabela 1. Parâmetros dos modelos ajustados aos valores de massa seca, nitrogênio, fósforo e potássio remanescentes, tempo de meia vida $\left(\mathrm{T}^{1 / 2}\right)$ de cada compartimento e valores de $\mathrm{r}^{2}$ de plantas de cobertura cada sistema.

\begin{tabular}{|c|c|c|c|c|c|c|}
\hline \multirow[t]{2}{*}{ Sistemas } & \multicolumn{2}{|c|}{$\mathbf{K}^{(\mathbf{1})}$} & \multicolumn{2}{|c|}{$T^{1 / 2(2)}$ Dias } & \multicolumn{2}{|c|}{$\mathbf{r}^{2}$} \\
\hline & $1^{\circ}$ avaliação & $2^{\circ}$ avaliação & $1^{\circ}$ avaliação & $2^{\circ}$ avaliação & $1^{\circ}$ avaliação & $2^{\circ}$ avaliação \\
\hline & \multicolumn{6}{|c|}{ Massa seca } \\
\hline SB & 0,0018 & 0,00700 & 385 & 99 & $0,78^{*}$ & $0,95^{*}$ \\
\hline \multirow[t]{2}{*}{ SS } & 0,0014 & 0,00600 & 495 & 115 & $0,87 *$ & $0,94 *$ \\
\hline & \multicolumn{5}{|c|}{$\mathbf{N}$} & \\
\hline SB & 0,0081 & 0,0153 & 85 & 42 & $0,70 *$ & $0,85^{*}$ \\
\hline \multirow[t]{2}{*}{ SS } & 0,0083 & 0,0103 & 85 & 67 & $0,65^{*}$ & $0,81 *$ \\
\hline & \multicolumn{5}{|c|}{$\mathbf{P}$} & \\
\hline SB & 0,0935 & 0,1801 & 8 & 4 & $0,89^{*}$ & $0,99 * *$ \\
\hline \multirow[t]{2}{*}{ SS } & 0,0974 & 0,1710 & 7 & 4 & $0,87 *$ & $0,98 * *$ \\
\hline & \multicolumn{5}{|c|}{$\mathbf{K}$} & \\
\hline SB & 0,0894 & 0,1377 & 8 & 5 & $0,96^{*}$ & $0,98 * *$ \\
\hline SS & 0,1203 & 0,1783 & 6 & 4 & $0,99 *$ & $0,99 * *$ \\
\hline
\end{tabular}

${ }^{(1)}$ Constante de decomposição; ${ }^{(2)}$ Tempo de meia vida. * e ** significativos a 5 e $1 \%$ pelo teste F. SB: sistemas soja/braquiária (SB); SS: sistema soja/sorgo.

Fonte: Elaboração dos autores. 
Os resultados mostram a grande importância do uso de gramíneas para a formação de palhada no Cerrado brasileiro, pois mesmo em condições de altas temperaturas e umidade, o material apresenta elevado $\mathrm{T}^{1 / 2}$. Desta forma, a palhada permanece no solo, fornecendo proteção física, umidade e contribuindo para o aumento dos teores de carbono orgânico no solo. Ao avaliar a decomposição e liberação de nutrientes de plantas de cobertura na região Noroeste Fluminense, Gama-Rodrigues, Gama-Rodrigues e Brito (2007) verificaram valores de $\mathrm{T}^{1 / 2}$ vida de massa seca remanescente de 115 dias para a braquiária e de 52 dias para feijão de porco, ressaltando a importância da gramínea na manutenção da palhada no solo. Fabian, Corá e Torres (2006), estudando plantas de cobertura no cerrado, observaram que as taxas de decomposição da braquiária foram mais intensas nos primeiros 90 dias de avaliação, restando $59 \%$ da matéria seca aos 120 dias após o início da avaliação.

Os conteúdos de N, P e K remanescentes nos resíduos vegetais, apresentaram o mesmo padrão observado para a massa seca, com uma fase inicial rápida seguida de outra mais lenta (Figuras 4, 5 e 6). A variação da liberação de N, P e K apresentou o mesmo padrão nas duas épocas avaliadas.

Figura 4. Nitrogênio remanescente dos resíduos de plantas de cobertura nos sistemas soja/braquiária (SB) e soja/ sorgo (SS), avaliados. Avaliações realizadas no campo até 120 dias após a distribuição das bolsas de decomposição na superfície do solo. Acondicionamento das sacolas de decomposição em março de 2007 (a) Acondicionamento das sacolas de decomposição em novembro de 2007 (b).

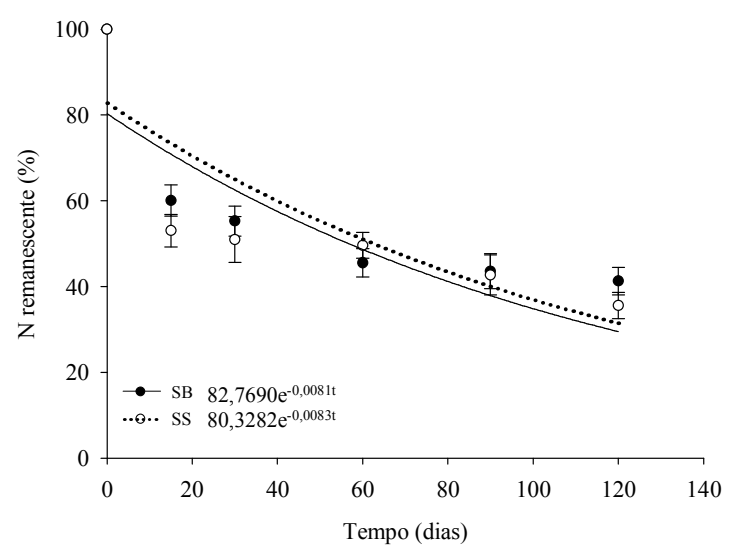

(a)

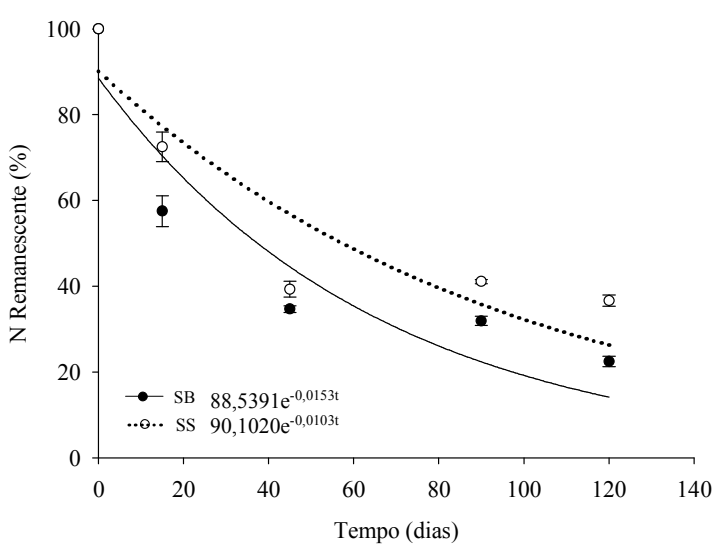

(b)

Fonte: Elaboração dos autores. 
Figura 5. Fósforo remanescente dos resíduos de plantas de cobertura nos sistemas soja/braquiária (SB) e soja/sorgo (SS), avaliados. Avaliações realizadas no campo até 120 dias após a distribuição das bolsas de decomposição na superfície do solo. Acondicionamento das sacolas de decomposição em março de 2007 (a) Acondicionamento das sacolas de decomposição em novembro de 2007 (b).

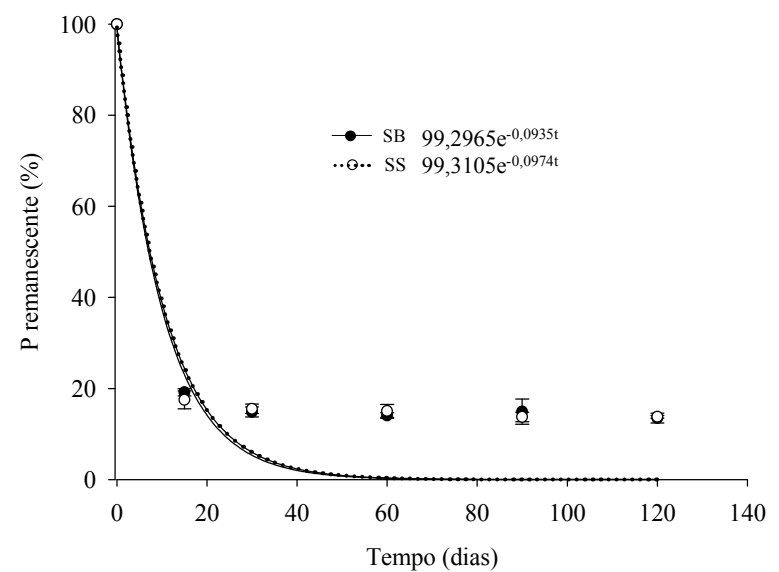

(a)

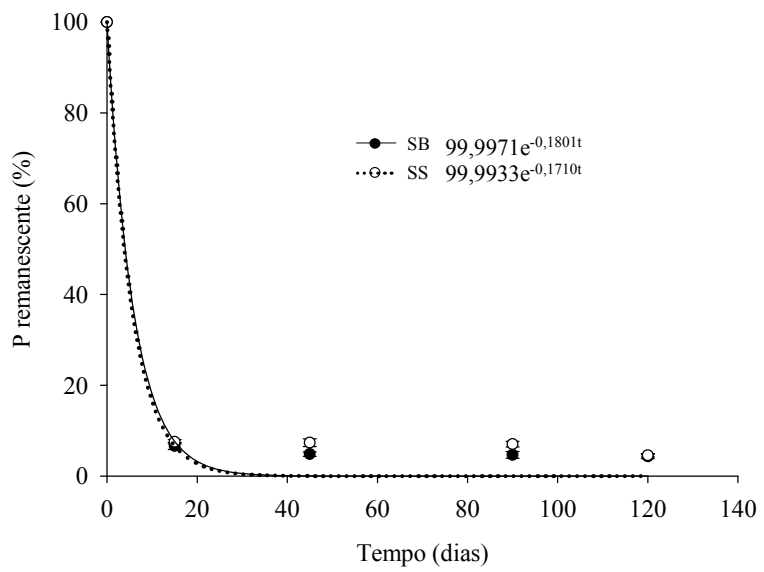

(b)

Fonte: Elaboração dos autores.

Figura 6. Potássio remanescente dos resíduos de plantas de cobertura nos sistemas soja/braquiária (SB) e soja/sorgo (SS), avaliados. Avaliações realizadas no campo até 120 dias após a distribuição das bolsas de decomposição na superfície do solo. Acondicionamento das sacolas de decomposição em março de 2007 (a). Acondicionamento das sacolas de decomposição em novembro de 2007 (b).

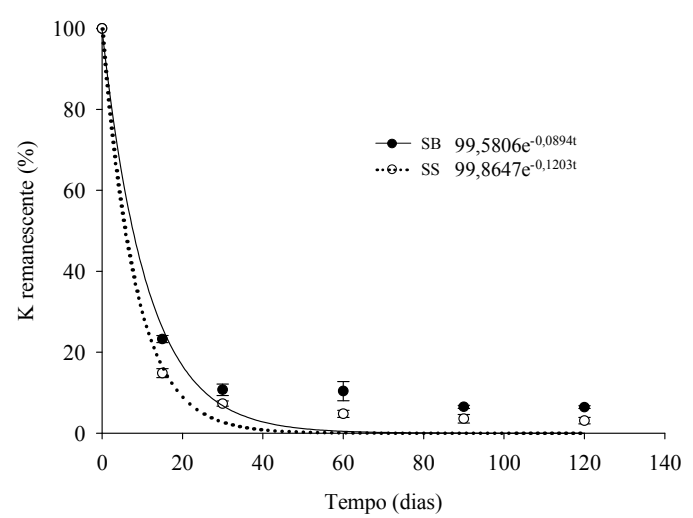

(a)

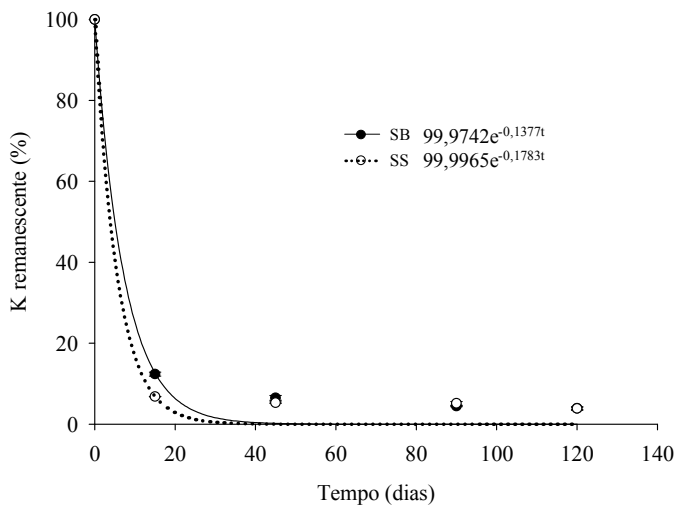

(b)

Fonte: Elaboração dos autores.

Ao estudar a decomposição e liberação de nitrogênio de resíduos culturais na região do Cerrado brasileiro, Torres et al. (2005) verificaram valores $\mathrm{T}^{1 / 2}$ de mineralização do $\mathrm{N}$ de 47 dias para braquiária e 141 dias para sorgo. Já em estudos de decomposição e liberação de nutrientes de plantas de cobertura na região Noroeste Fluminense,
Gama-Rodrigues; Gama-Rodrigues e Brito (2007) verificaram $\mathrm{T}^{1 / 2}$ de $\mathrm{N}$, P e K para braquiária adubada de 131,112 e 21 dias, respectivamente.

$\mathrm{A}$ rápida liberação de $\mathrm{P}$ no período inicial da decomposição está relacionada à perda de $\mathrm{P}$ solúvel emágua acumulado nos vacúolos dos tecidos vegetais 
da planta (BUCHANAN; KING, 1993). Esta rápida liberação pode contribuir para aumentar a eficiência do $\mathrm{P}$, diminuindo sua imobilização microbiana, e sua fixação pelos óxidos de ferro (FROSSARD et. al., 1995). Para o K, a liberação ocorrida nos primeiros dias foi corroborada pelos resultados de Da Ros (1993), Moreira (2003) e Giacomini et al. (2003), e pode ser atribuída ao fato de o K não estar associado a nenhum componente estrutural do tecido vegetal das plantas e a mineralização não ser um pré-requisito para sua liberação (COSTA; GAMA-RODRIGUES; CUNHA, 2005).

Estudando a dinâmica do $\mathrm{K}$ em resíduos culturais no Cerrado, Torres e Pereira (2008) verificaram maiores $\mathrm{T}^{1 / 2}$ quando comparados aos encontrados nesse estudo, com valores variando de 73 dias para braquiária e de 114 dias para o sorgo.

Vale ressaltar que em regiões tropicais a manutenção dos resíduos culturais no solo é de grande relevância, não só com o objetivo de sincronizar a oferta de nutrientes pelas plantas de cobertura com a demanda pelas culturas comerciais, mas para a manutenção da umidade e da proteção física contra a erosão (DERPSCH; SIDIRAS; HEINZMANN, 1985; CALEGARI et. al., 1993; SANTOS et al., 2007).

\section{Conclusões}

A produção de biomassa seca da palhada da braquiária + soja foi superior a da palhada sorgo + soja, mostrando a eficiência da braquiária em ser utilizada como planta de cobertura para o cerrado goiano.

O cultivo de soja sobre palhada de braquiária apresentou maior taxa de decomposição dos resíduos e um menor tempo de meia vida quando comparada a soja cultivada sobre palhada de sorgo.

A cinética da liberação de $\mathrm{N}, \mathrm{P}$ e $\mathrm{K}$ dos resíduos de soja e braquiária foi semelhante a dos resíduos de soja e sorgo nas duas épocas avaliadas.

\section{Agradecimentos}

Os autores agradecem o apoio do CPGA-CS / UFRRJ, CNPq, Fazenda Querência das Antas.

\section{Referências}

AITA, C.; GIACOMINI, S. J. Decomposição e liberação de nitrogênio de resíduos culturais de plantas de cobertura de solo solteiras e consorciadas. Revista Brasileira de Ciência do Solo, Viçosa, v. 27, n. 4, p. 601-612, 2003.

BAYER, C.; MIELNICZUK, J.; MARTIN-NETO, L.; PAVINATO, A. Armazenamento de carbono em frações lábeis da material orgânica de um Latossolo Vermelho sob plantio direto. Pesquisa Agropecuária Brasileira, Brasília, v. 39, n. 7, p. 677-683, 2004.

BORLAUG, N. E. Feeding a world of 10 billion people: the miracle ahead. In: BAILEY, R. (Ed.). Global warming and other eco-myths. Roseville, EUA: Competitive Enterprise Institute, 2002. p. 29-60.

BUCHANAN, M.; KING, L. Carbon and phosphorus losses from decomposing crop residues in no till and conventional till agroecosystems. Agronomy Journal, Madison, v. 85, n. 3, p. 631-638, 1993.

CALEGARI, A.; MONDARDO, A.; BULIZANI, E. A.; COSTA, M. B. B.; MIYSAKA, S.; AMADO, T. J. C. Aspectos gerais da adubação verde. In: COSTA, M. B. B. (Org.). Adubação verde no sul do Brasil. Rio de Janeiro: AS-PTA, 1993. p. 1-55.

CERETTA, C. A.; BASSO, C. J.; FLECHA, A. M. T.; PAVINATO, P. S.; VIEIRA, F. C. B.; MAI, M. E. M. Manejo da adubação nitrogenada na sucessão aveia preta/milho, no sistema plantio direto. Revista Brasileira de Ciência do Solo, Viçosa, v. 16, n. 1, p. 163-171, 2002.

CORREIA, J. R.; REATTO, A.; SPERA, S. T. Solos e suas relações com o uso e o manejo. In: SOUSA, D. M. G.; LOBATO, E. Cerrado: correção do solo e adubação. 2. ed. Brasília, DF: Embrapa Informação Tecnológica, 2004. p. 29-58.

COSTA, G. S.; GAMA-RODRIGUES, A. C.; CUNHA, G. M. Decomposição e liberação de nutrientes da serapilheira foliar em povoamentos de Eucalyptus grandis no norte fluminense. Revista Árvore, Viçosa, v. 29, n. 4, p. 563-570, 2005.

CRUSCIOL, C. A. C.; SORATTO, R. P. Nutrição e produtividade do amendoim em sucessão ao cultivo de plantas de cobertura no sistema plantio direto. Pesquisa Agropecuária Brasileira, Brasília, v. 42, n. 11, p. 15531560, 2007. 
DA ROS, C. O. Plantas de inverno para cobertura do solo e fornecimento de nitrogênio ao milho em plantio direto. 1993. Dissertação (Mestrado em Agronomia) Universidade Federal de Santa Maria, Santa Maria.

DERPSCH, R.; SIDIRAS, N.; HEINZMANN, F. X. Manejo do solo com coberturas verdes de inverno. Pesquisa Agropecuária Brasileira, Brasília, v. 20, n. 7, p. 761-773, 1985.

\section{EMPRESA BRASILEIRA DE PESQUISA} AGROPECUÁRIA - EMBRAPA. Sistema brasileiro de classificação de solos. 2. ed. Brasília: Embrapa Produção de Informação; Rio de Janeiro: Embrapa Solos, 2006. $312 \mathrm{p}$.

ESPÍNDOLA, J. A.; GUERRA, J. G. M.; ALMEIDA, D. L.; TEIXEIRA, M. G.; URQUIAGA, S.; PERIN, A. Decomposição in situ da parte aérea de algumas leguminosas perenes usadas como cobertura viva do solo. In: FERT BIO98, 1998, Caxambú. Anais... Caxambú: UFLA/SBCS/SBM, 1998b. p. 110.

FABIAN, A. J.; CORÁ, A. J.; TORRES, J. L. R. Plantas de cobertura: produção de fitomassa, decomposição e porcentagem de cobertura do solo. In: REUNIÃO BRASILEIRA DE MANEJO E CONSERVAÇÃO DO SOLO E ÁGUA, 16., Aracaju, 2006. Anais... Aracaju: SBCS/Embrapa Tabuleiros Costeiros/UFS, 2006. CDROM.

FREIXO, A. A.; CANELLAS, L. P.; MACHADO, P. L. O. A. Propriedades espectrais da matéria orgânica leve livre e leve intra-agregado de dois Latossolos sob plantio direto e preparo convencional. Revista Brasileira de Ciência do Solo, Viçosa, v. 26, n. 2, p. 445-453, 2002.

FROSSARD, E.; FROSSARD, M.; HEDLEY, M. J.; MATHERELL, A. Reactions controlling the cycling of $P$ in soil. In: TIESSNM, H. (Org.). Phosphorus in the global environment: transfers, cycles and management. Chichester: J. Wiley, 1995. p. 107-146.

GAMA-RODRIGUES, A. C.; GAMA-RODRIGUES, E. F.; BRITO, E. C. Decomposição e liberação de nutrientes de resíduos culturais de plantas de cobertura em Argissolo Vermelho-Amarelo na Região Noroeste Fluminense (RJ). Revista Brasileira de Ciência do Solo, Viçosa, v. 31, n. 6, p. 1421-1428, 2007.

GIACOMINI, S. J.; VENDRUSCOLO, E. R. O.; CUBILlA, M.; NICOLOSO, R. S.; FRIES, M. R. Matéria seca, relação $\mathrm{C} / \mathrm{N}$ e acúmulo de nitrogênio, fósforo e potássio em misturas de plantas de cobertura do solo, Revista Brasileira de Ciência do Solo, Viçosa, v. 27, n. 2, p. 325-334, 2003.

HILDEBRAND, C. Manual de métodos de análises químicas de solo e plantas. Curitiba: Universidade Federal do Paraná, 1976. 225 p.
KLIEMANN, J. H.; BRAZ, A. J. P. B.; SILVEIRA, P. M. Taxas de decomposição de resíduos de espécies de cobertura em Latossolo Vermelho Distroférrico. Pesquisa Agropecuária Tropical, Goiânia, v. 36, n. 1, p. 21-28, 2006.

LAL, R.; LOGAN, T. J. Agricultural activities and greenhouse gas emissions from soils of the tropics. In: LAL, R.; KIMBLE, J. M.; LEVINE, E.; STEWART, B. A. (Ed.). Soil management greenhouse effect. Boca Raton: CRC Press, 1995. p. 293-307.

MORAES, R. N. S. Decomposição das palhadas de sorgo e milheto, mineralização de nutrientes e seus efeitos no solo e na cultura do milho em plantio direto. 2001. Dissertação (Mestrado em Solos e Nutrição de Plantas) - Universidade Federal de Lavras, Lavras.

MOREIRA, F. M. de S.; SIQUEIRA, J. O. Microbiologia e bioquímica do solo. Lavras: UFLA, 2002. 626 p.

MOREIRA, V. F. Produção de biomassa de guandu a partir de diferentes densidades de plantio e cultivo de brócolos em faixas intercalares sob manejo orgânico. 2003. Dissertação (Mestrado em Fitotecnia) Universidade Federal Rural do Rio de Janeiro, Rio de Janeiro.

NUNES, U. R.; ANDRADE JÚNIOR, V. C. A.; SILVA, E. B.; SANTOS, N. F.; COSTA, H. A. O.; FERREIRA, C. A. Produção de palhada de plantas de cobertura e rendimento do feijão em plantio direto. Pesquisa Agropecuária Brasileira, Brasília, v. 41, n.6, p. 943-948, 2006.

OLIVEIRA, T. K. Plantas de cobertura em cultivo solteiro e consorciado e seus efeitos no feijoeiro e no solo em plantio direto. 2001. Dissertação (Mestrado em Agronomia) - Universidade Federal de Lavras, Lavras.

REID, J. B.; GOSS, M. J. Changes in the aggregate stability of a sandy loam effected by growing roots of perennial ryegrass (Lolium perene). Journal of the Science of Foods and Agriculture, London, v. 31, n. 2, p. 325-328, 1980.

SANTOS, T. E. M.; MONTENEGRO, A. A.; SILVA. E. F. F.; LIMA NETO, J. A. Perdas de carbono orgânico, potássio e solo em Neossolo Flúvico sob diferentes sistemas de manejo no semi-árido. Revista Brasileira de Ciências Agrárias, Recife, v. 2, n. 2, p. 143-149, 2007.

SILVA, M. L. N.; CURI, N.; BLANCANEAUX, P.; LIMA, J. M.; CARVALHO, A. M. Rotação adubo verde - milho e adsorção de fósforo em Latossolo VermelhoEscuro. Pesquisa Agropecuária Brasileira, Brasília, v. 32, n. 6, p. 649-654, 1997. 
SILVA, T. O. da; FURTINI NETO, A. E.; CARNEIRO, L. F.; PALUDO, V. Plantas de cobertura submetidas a diferentes fontes de fósforo em solos distintos. Semina: Ciências Agrárias, Londrina, v. 32, n. 4, p. 1315-1326, 2011.

TEDESCO, M. J.; VOLKWEISS, S. J.; BOHNEN, H. Análise de solo, plantas e outros materiais. Porto Alegre: Faculdade de Agronomia, Universidade Federal do Rio Grande do Sul, 1985. 188 p. (Boletim técnico de solos, 5).

THOMAS, R. J.; ASAKAWA, N. M. Decomposition of leaf litter from tropical forage grasses and legumes. Soil Biology \& Biochemistry, Oxford, v. 25, n. 10, p. 13511361, 1993.
TORRES, J. L. R.; PEREIRA, M. G. Dinâmica do potássio nos resíduos vegetais de plantas de cobertura no cerrado. Revista Brasileira de Ciência do Solo, Viçosa, v. 32, n. 4, p. 1609-1618, 2008.

TORRES, R. J. L.; PEREIRA, M. G.; ANDRIOLI, I.; POLIDORO, J. C.; FABIAN, A. J. Decomposição e liberação de nitrogênio de resíduos culturais de plantas de cobertura em um solo de cerrado. Revista Brasileira de Ciência do Solo, Viçosa, v. 29, n. 4, p. 609-618, 2005. 
